\title{
Educa Trânsito - Um jogo de apoio à educação no trânsito
}

John Wisley da Silva - Ifes, johnwisley1@gmail.com

Diego Soares Rodrigues - Ifes, diegosoaresub@gmail.com

Dyego Dantas - Ifes, dyegod3@gmail.com

Vanessa Battestin Nunes - Ifes, vanessa@ifes.edu.br

Isaura Alcina Martins Nobre - Ifes, isaura@ifes.edu.br

\begin{abstract}
Resumo. Esse artigo apresenta o Educa Trânsito, um jogo educativo cujo objetivo é contribuir para a educação no trânsito, permitindo que o jogador exercite hábitos e atitudes de respeito ao próximo, normas sociais e leis de trânsito, colocando-se hora no lugar de um motorista, hora no de um pedestre. O jogo é uma ferramenta livre, cujo público alvo são pessoas alfabetizadas maiores de 10 anos. É apresentado como uma ferramenta de apoio ao processo educacional na formação de cidadãos mais responsáveis $e$ conscientes dos benefícios de se cultivar um trânsito mais seguro. Foi construído segundo a metodologia XisOA e, posteriormente, avaliado por uma especialista, que apontou aspectos positivos no jogo e pontos de melhoria.
\end{abstract}

Palavras-chave: jogo educativo, educação no trânsito, tecnologia educacional

\section{Educa Trânsito - A game to support traffic education}

\begin{abstract}
This article presents the Educa Trânsito, an educational game whose objective is to contribute to the traffic educacation, allowing the player to exercise habits and attitudes of respect for others, social norms and transit laws. The game is a free tool whose target audience is literate people older than 10 years. It is presented as a tool to support the educational process in the formation of citizens more responsible and aware of the benefits of cultivating a safer transit. It was built according to the methodology XisOA and later evaluated by an expert, who pointed out positive aspects in the game and points for improvement.
\end{abstract}

Key-words: educational game, traffic education, educational technology

\section{Introdução}

De acordo com o Centro de Estudos sobre as Tecnologias da Informação e da Comunicação (Cetic.br), em 2012, 40\% das residências brasileiras já tinham acesso a internet, sendo que esse percentual era de 36\% em 2011 (CETIC, 2012). O Instituto Brasileiro de Geografia e Estatística (IBGE) divulgou, também, dados relativos ao uso dos telefones celulares e internet no Brasil, que demonstram um aumento superior a $100 \%$ entre os anos de 2005 e 2011. Esses dados demonstram que as tecnologias estão se tornando mais acessíveis aos brasileiros (IBGE, 2011).

Nessa realidade, ganha destaque o mercado de jogos, que por meio de sua variedade, desde os mais simples aplicativos para celular aos mais sofisticados feitos por grandes empresas, invadem o cotidiano das pessoas. Todavia, a maioria dos jogos 
disponíveis tem a função apenas de entretenimento, não buscando agregar alguma informação educativa. Outros jogos que buscam a função de educar muitas vezes se limitam a um papel meramente conteudista, o que o torna pouco atrativo, maçante e tende a não despertar o interesse dos usuários.

Esse artigo apresenta um jogo educativo que aborda a educação no trânsito, assunto de relevância a ser tratado no Brasil. O jogo tem o intuito de mostrar as consequências geradas pela imprudência e falta de conhecimento em algumas situações no trânsito, representadas no jogo por cenários, pré-definidos, que trazem para o jogador questionamentos sobre como proceder e opções relacionadas a tais situações estando o jogador no papel de motorista ou pedestre. Objetiva, também, fomentar no cidadão a prática de ser educado no trânsito, quando em convívio com outras pessoas, seguindo a orientação de Hoffmann (2003), que em seu livro propôs que a educação no trânsito não dever se resumir apenas a oferta de conteúdo de instrução, como normas de circulação, recomendações práticas ou dados como número de mortos, acidentes e feridos. Ela fala que a educação para o trânsito se trata de criar e exercitar hábitos e atitudes a partir da formação da criança e do adolescente, para que se tornem cidadãos responsáveis pela própria sobrevivência, que respeitem aos demais e as normas sociais quando assumires papéis seja de pedestre, condutor ou passageiro.

A seguir, discutimos sobre jogos educativos, educação para o trânsito, apresentamos a metodologia e o processo utilizados no trabalho, o jogo construído: Educa Trânsito, a avaliação por um especialista e, por fim, as conclusões do trabalho.

\section{Jogos educativos}

Cada indivíduo não é dotado de um mesmo conjunto de competências. Consequentemente, nem todos aprendem da mesma forma, segundo a teoria das múltiplas inteligências de Gardner (1985). Resta ao educador descobrir mecanismos de interação que contribuam para o desenvolvimento intelectual de seus alunos.

Após a virada do século, computadores e dispositivos eletrônicos que se utilizam de processamento se tornaram comuns no dia-dia da população, transformando-se em hábitos cotidianos na vida da sociedade. No que diz respeito aos tipos de aplicações utilizadas pelos usuários, destacam-se as que geram entretenimento, tornando-se uma tendência fortalecida pelo mercado de jogos digitais. Neste contexto, deve-se refletir a respeito da utilidade da computação por meio de jogos digitais no contexto educacional.

Em seu artigo sobre jogos educativos, Pereira e Passos (2012, p. 318) citam uma definição de jogos proposta por Huizinga, na qual o jogo é visto como uma atividade composta por três características fundamentais: Ser uma atividade voluntária que exige e leva à liberdade; uma atividade que leva a uma realidade fictícia; e uma atividade que, apesar das características anteriores, pode absorver o jogador de maneira intensa e total.

Assim, os jogos, em geral, por meio de sua ludicidade, promovem um ambiente motivacional, no qual fica evidente a importância da interface e da interatividade. $\mathrm{O}$ fato de o controle estar nas mãos do usuário, na sua capacidade de alcançar níveis cada vez maiores de dificuldade é outro fator motivacional quanto a sua utilização.

Características do jogo na qual o jogador pode sentir emoções desencadeadas pelas atitudes tomadas no ambiente fictício, onde ele pode "viver" experiências decorrentes de suas decisões nesse mundo imaginário, lúdico, e ver suas consequências, que podem ser semelhantes as do mundo real, sem danos reais, fazem do jogo uma ótima ferramenta educacional. Moratori (2003, p.09) diz que o jogo pode ser um 
importante meio educacional, pois propicia um desenvolvimento integral e dinâmico nas áreas cognitiva, afetiva, linguística, social, moral e proporciona o desenvolvimento da autonomia, criticidade, criatividade, responsabilidade e cooperação com outros.

Atualmente, podemos encontrar os mais variados tipos de jogos digitais, em sua maioria de caráter comercial, com foco no lucro e não em estruturas pedagógicas, para entretenimento, sejam na internet, desktop, mobile ou consoles. O que se deve buscar na abordagem de jogos digitais educativos é aproveitar o sucesso obtido pelos jogos em geral e adequar seus conceitos para incorporá-los ao processo educacional.

\section{Educação para o trânsito}

O Código Brasileiro de Trânsito (1997), Capítulo l, art 1º define Trânsito como: “[...] a utilização das vias por pessoas, veículos e animais, isolados ou em grupos, conduzidos ou não, para fins de circulação, parada, estacionamento e operação de carga ou descarga”. Apesar de ser uma definição técnica, que não fala claramente da interação entre os vários componentes de um sistema de trânsito, ela é bastante abrangente no sentido de defini-lo como sendo a utilização pelos mais variados personagens, pessoas, veículos e animais em suas diferentes condições e estados.

No entanto, no artigo de revisão de Macedo (2006, p.21) é citada uma definição de trânsito de Rozestranten como: “O conjunto de deslocamentos de pessoas e veículos nas vias públicas, dentro de um sistema convencional de normas, que tem por fim assegurar a integridade de seus participantes”. Pode-se notar aqui uma definição mais direcionada à interação entre as pessoas na qual menciona um sistema de normas para um bem comum aos que compõem o trânsito. Em conformidade com isso, Macedo define o trânsito, ainda, como “[...] um fenômeno multideterminado e multideterminante" e que é regido, além das normas de conduta estabelecidas pelo CBT, por normas de conduta formais e informais aonde o seu cumprimento, ou não cumprimento, influenciam o que está ao redor. Portanto, como as consequências provocadas pelas ações de um indivíduo atingem todos ao seu redor, para um bom convívio social entre as pessoas quando estiverem no trânsito, se faz necessário um processo contínuo de se educar e reeducar adultos, crianças e adolescentes para que se tenham motoristas, pedestres e passageiros mais conscientes da importância de sua cooperação e contribuição para um trânsito mais seguro.

Todavia, a educação para o trânsito não é tarefa simples. Segundo Hoffmann (2013, p.109), “[...] não é essencialmente uma parte integrante da educação social ou da educação moral da pessoa, porém delas se deriva, toma seus métodos e procedimentos para despertar a consciência cidadã dos alunos.” Ela também fala que a educação para o trânsito: "[...] é um aspecto a mais da educação ético-social, entendida como um conjunto de valores, normas, princípios, hábitos, que determina e ajuda a possibilitar a convivência social entre as pessoas, mas com um conteúdo próprio”.

\section{Metodologia e o processo de construção do jogo}

Para o desenvolvimento desse trabalho, inicialmente foi feita uma pesquisa bibliográfica sobre: jogos educativos, educação no trânsito e orientações do MEC (Ministério da Educação) quanto à abordagem da educação no trânsito nas escolas. A seguir, foi realizada uma busca por jogos correlatos, na intenção de fazer um jogo diferente da maioria dos encontrados sobre este tema que, de forma geral, priorizavam a memorização das leis de trânsito ou a formação dos motoristas. O mais próximo da 
abordagem aqui pretendida foi o jogo EducaTrans (ASSIS et al., 2006), em que o jogador assume uma função (pedestre, motorista ou ciclista) e tem o objetivo de chegar a um destino no menor tempo possível, sendo prudente e estando atento às placas de trânsito. No presente trabalho, porém, não quisemos limitar o usuário a um tempo, mas ao contrário, possibilitar à reflexão sofre opções de ação e suas consequências.

Foi utilizada a metodologia XisOA no desenvolvimento do trabalho proposto. Essa metodologia possui características do processo de desenvolvimento de software XP (Extreme Programming) e do Modelo RIVERD (2009). Foi proposto por Nobre e Nascimento (2009) na busca de uma alternativa mais coerente às peculiaridades do desenvolvimento de OAs (Objetos de Aprendizagem).

$\mathrm{Na}$ primeira fase do projeto instrucional - o projeto geral buscou-se estabelecer e descrever os objetivos que se esperava atingir com o OA, as habilidades e conhecimentos prévios, além das estratégias pedagógicas e se essas estavam de acordo com as orientações do DENATRAN e MEC. Ainda na primeira fase, para se delimitar o escopo do OA e uma maior compreensão do problema, foi feito um mapa conceitual do projeto no qual foram definidos os conceitos e seus relacionamentos (Figura 1).

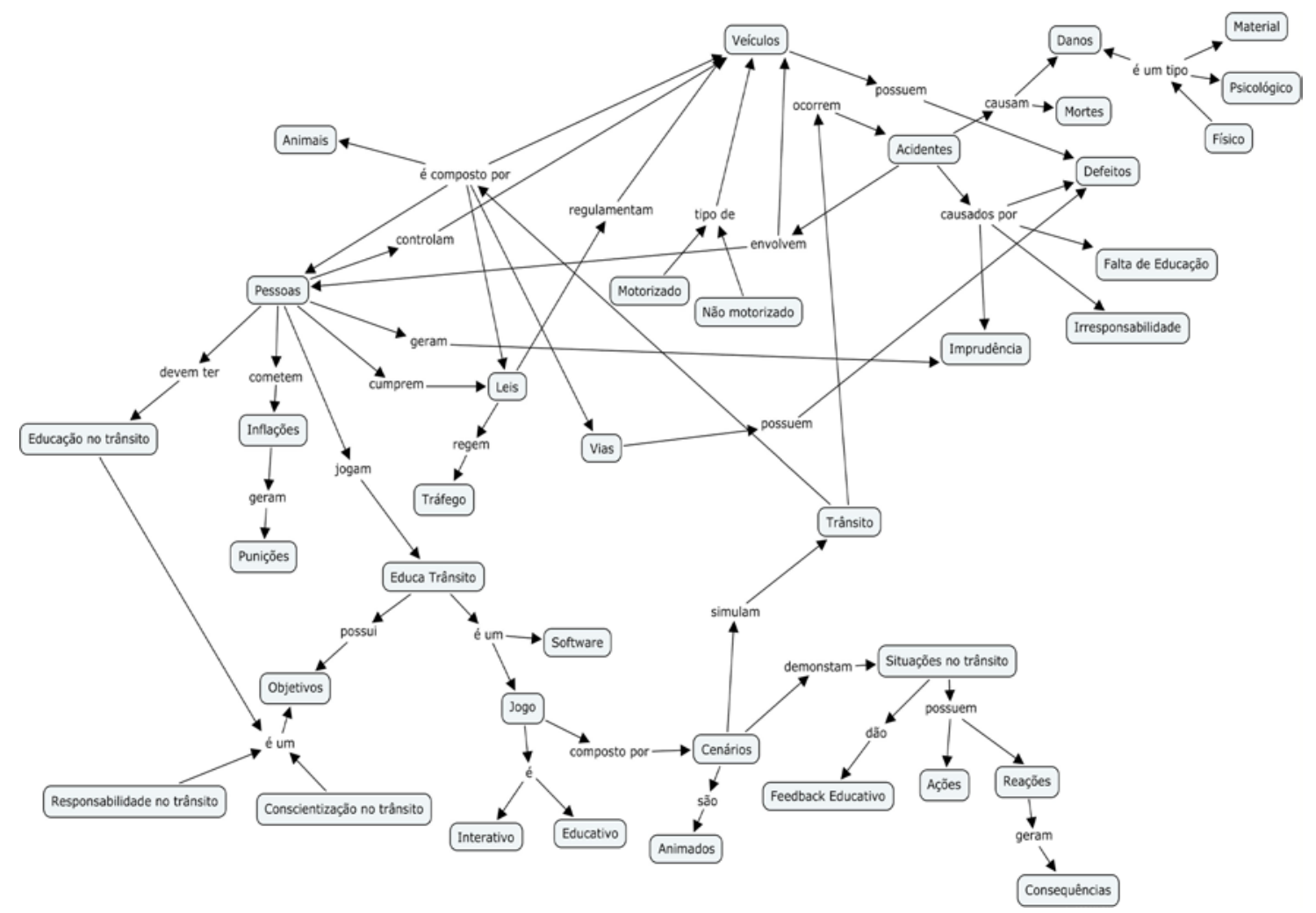

Figura 1- Mapa Conceitual Projeto

Utilizando a técnica Brainstorming, foram levantados os possíveis cenários, dos quais, após análise de cada caso, foram escolhidos os mais relevantes para a fase de implementação. Os cenários foram descritos por meio de um texto explicando seu contexto, as opções de ação fornecidas ao jogador, os feedbacks que seriam dados na escolha de cada opção e os protótipos de suas telas.

De forma resumida, entre os cenários descritos estão as seguintes situações:

1. Após um atropelamento o motorista deve decidir qual atitude adotar diante uma pessoa ferida no local. Exemplo de opção: Socorrer a vítima. 
2. Parada em um semáforo vermelho e uma ambulância, devidamente sinalizada, pede passagem. Exemplo de opção: Esperar o semáforo abrir.

3. O trânsito está parado e o pedestre longe da faixa de pedestre pretende atravessar. Exemplo de opção: Atravessar entre os carros parados.

4. Uma situação em que o motorista pode fechar o cruzamento se não estiver atento ao semáforo e ao fluxo da via. Exemplo de opção: Deixar o cruzamento livre mesmo com o semáforo aberto.

5. Um pedestre pede passagem em um local inapropriado para atravessar a pista. Neste cenário é apresentado opções de procedimento, tanto para o motorista como para o pedestre. Exemplo de opção para o motorista: Não parar o carro. E exemplo para o pedestre: Procurar um local apropriado para atravessar.

6. O semáforo fica amarelo e o motorista com o carro em movimento, a uma certa distância do semáforo. Exemplo de opção: Tentar parar o carro.

7. O motorista se depara com cavalos na pista. Exemplo de opção para o motorista: Buzinar para que os animais saiam da pista.

O jogo foi implementado utilizando a IDE Unity, a linguagem JavaScript sendo que o Blender e o adobe Fireworks CS6 foram usados como ferramenta de apoio. A utilização da IDE Unity permitiu criar um jogo multiplataforma que em sua versão web funciona em todo computador que tenha conexão com internet, necessitando apenas que o plugin Unity player seja instalado no navegador do computador. Até o presente momento, os últimos três cenários do jogo foram implementados. Após seu desenvolvimento e testes, o jogo foi apresentado a uma especialista da área de educação para avaliar o alcance dos objetivos propostos, além de receber suas considerações e sugestões de melhorias.

\section{O jogo Educa Trânsito}

O jogo Educa Trânsito procura mostrar as consequências das atitudes das pessoas no trânsito e, com isso, estimular a reflexão sobre o problema da falta de educação e respeito, além de agregar conhecimento que possa ser colocado em prática na vida real.

Como o jogo mostra algumas imagens que tentam retratar possíveis consequências das tomadas de decisões do jogador, entre elas as que provocam acidentes, o público alvo desse jogo não abrange crianças menores de 10 anos, podendo ser jogado por pessoas acima dessa idade que saibam ler e manusear o mouse, habilidades prévias exigidas.

O jogo, em sintonia com orientações do DENATRAN sobre educação no trânsito, não tem como objetivo formar futuros motoristas, portanto, esse jogo não atende aos que buscam treinamento para se preparar para tirar a CNH. A aparência dos cenários foram inteiramente criadas por um dos membros do grupo, no entanto, no caso dos objetos 3D, como os carros, animais e personagens, foram utilizados modelos livres para uso acadêmico.

Ao iniciar o jogo a Figura 2 é apresentada ao jogador. Na criação dessa tela foi utilizada, como base, uma imagem disponível em um blog informativo sobre educação no trânsito o www.detran.pe, que foi personalizada por meio da adição de textos e novas figuras à imagem original. Essa tela inicial permite visualizar e selecionar as opções ("Sobre", "Config” e "Jogar") e, a medida em que o jogador passa o cursor do mouse 
sobre uma das opções, é acesa a luz correspondente no semáforo. A opção "Sobre” traz informações sobre como jogar e objetivo do jogo, "Config” dá opção de tamanho de tela, volume, resolução entre outras e ao clicar em “Jogar” o jogo inicia.

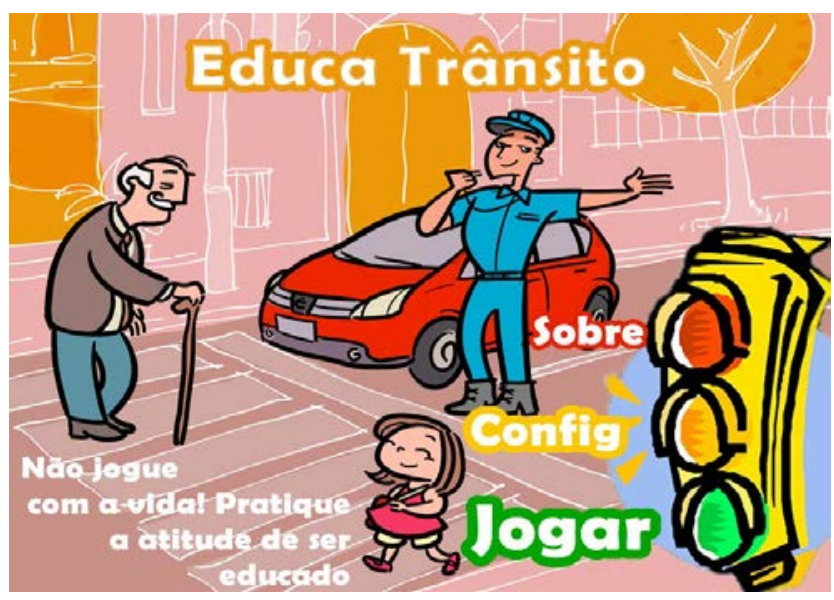

Figura 2. Tela Inicial do jogo Educa Trânsito.

Ao iniciar o jogo, um cenário é apresentado ao jogador. Os cenários são animados e, em certo momento, aparece um texto explicando a situação, como na Figura 3: "Carros transitam normalmente na pista, quando de repetente um pedestre vai em direção à pista com o objetivo de fazer a travessia.”

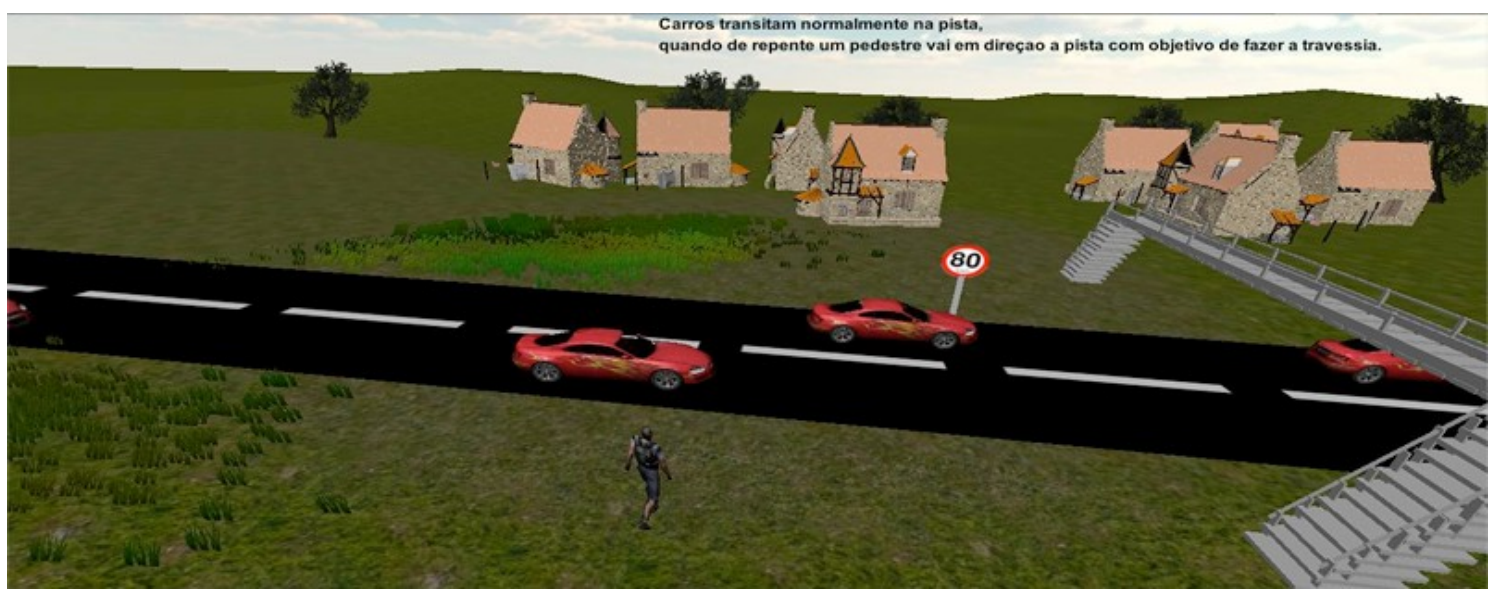

Figura 3. Tela Inicial de um cenário com a descrição da situação.

A seguir, são apresentadas as opções de possíveis reações do jogador. Nesse cenário, o jogador é posto na posição do motorista, que visualiza um pedestre pedindo passagem (Figura 4) e lhe é perguntado como procederia. As opções são: (1) "Ignorar o pedestre e prosseguir a viagem"; (2) "Parar o carro para dar passagem ao pedestre"; (3) Diminuir a velocidade abaixo do permitido para orientar o pedestre verbalmente. 


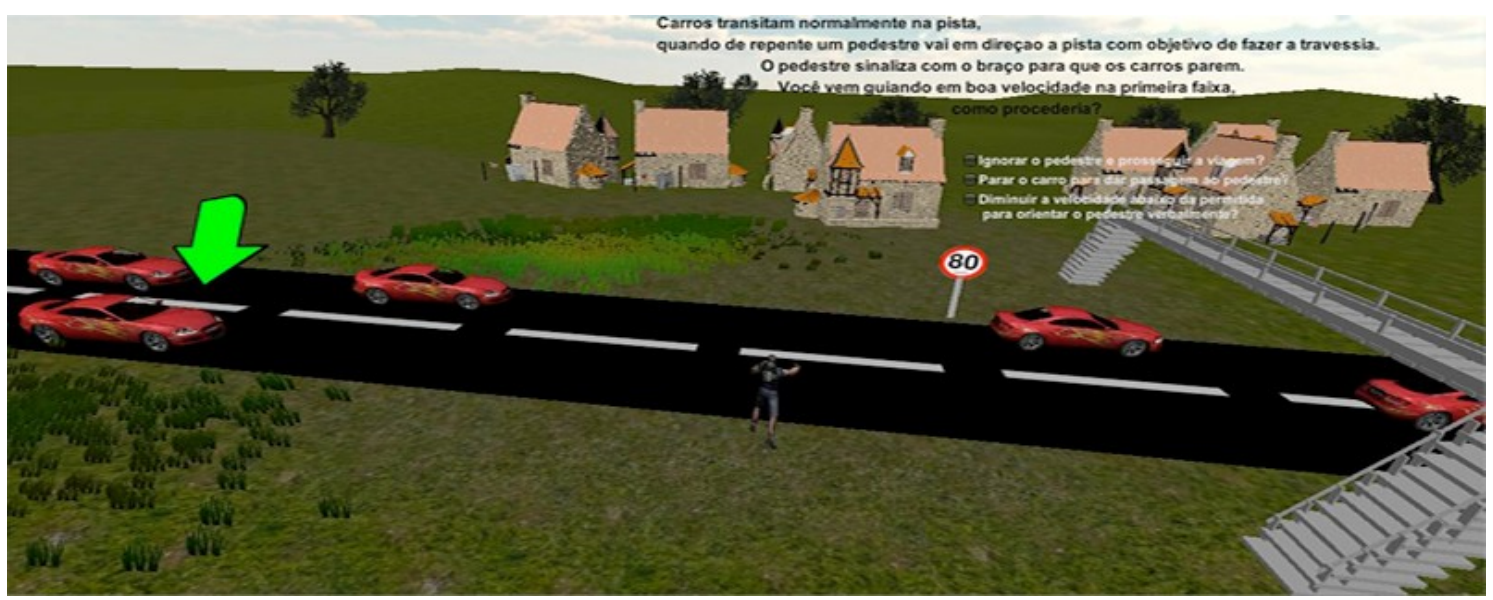

Figura 4. Tela que apresenta as opções de possíveis reações do jogador.

Após a escolha de uma das opções, a animação continua dando um desfecho. No caso da Figura 5, o jogador optou por parar o carro no meio da via, o que, como consequência de sua escolha, provocou um acidente. A seguir, é apresentado um feedback ao jogador: "A intenção foi boa, porém as vias possuem velocidade mínima e reduzir a velocidade abaixo da mínima permitida também pode causar acidente”.

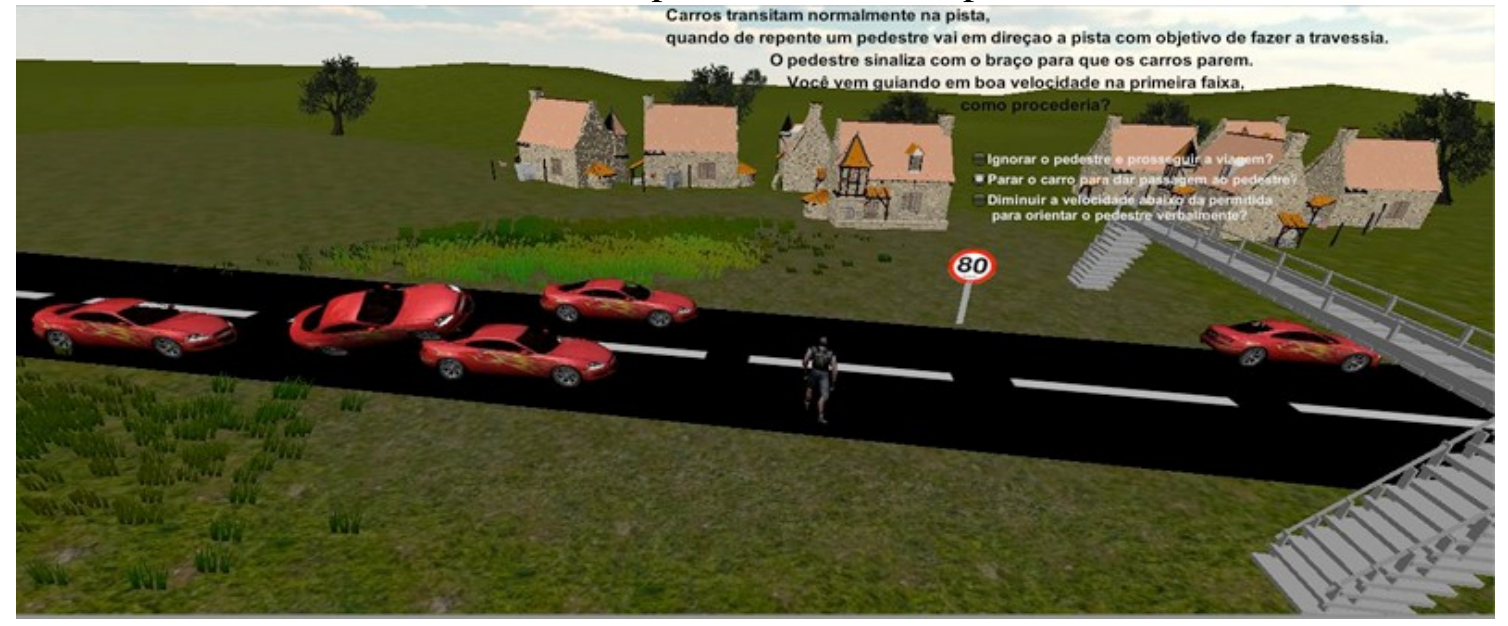

Figura 5. Tela mostra um dos desfechos do cenário.

No caso desse cenário, é apresentado, também, ao jogador opções de como ele, se estivesse no papel de pedestre, poderia ter evitado o acidente. Neste caso, a resposta correta seria utilizando a passarela, que encontra-se poucos metros a frente.

O objetivo final desse jogo é, então, apoiar o processo educacional na formação de cidadãos mais responsáveis e conscientes de suas atitudes no trânsito, seja na posição de motorista, seja de pedestre. Visando, assim, de alguma forma contribuir para um mundo mais pacífico no trânsito, diferente do momento atual, em que um simples buzinar tem causado diversas brigas e mortes.

\section{Avaliação por um especialista}

Para uma melhor análise sobre o impacto educacional do jogo, convidamos uma especialista da área de educação para avaliá-lo. Para isso, foi desenvolvido um questionário com 17 questões baseado nos trabalhos (ALBERNAZ, 2008) e (NOBRE et al., 2011), destacando requisitos de usabilidade e pedagógicos, tendo como possíveis respostas: atende plenamente, atende parcialmente, não atende e não se aplica. Além 
disso, foi deixado um espaço para a avaliadora fazer suas considerações e sugestões para melhorias do jogo (Tabela 1 ).

A avaliadora é doutora em educação e professora há mais de 20 anos, atuando em ensino médio e superior, nas modalidades presencial e a distância. Para realizar a avaliação, ela inicialmente interagiu com o jogo sozinha, sem auxílio da equipe desenvolvedora. Posteriormente, ela pode sanar algumas dúvidas e dar sugestões de melhoria. O resultado de sua avaliação consta na Tabela 1.

Tabela 1. Avaliação do jogo por uma especialista.

\begin{tabular}{|c|c|c|c|c|}
\hline REQUISITOS & Atende & $\begin{array}{l}\text { Atende } \\
\text { Parcialm } \\
\text { ente }\end{array}$ & $\begin{array}{l}\text { Não } \\
\text { Atende }\end{array}$ & $\begin{array}{l}\text { Não se } \\
\text { aplica }\end{array}$ \\
\hline \multicolumn{5}{|l|}{ Requisitos de Usabilidade } \\
\hline $\begin{array}{l}\text { 1. A linguagem é adequada ao público alvo definido e ao nível de ensino a } \\
\text { que se refere. }\end{array}$ & & $x$ & & \\
\hline 2. É atrativo, envolvendo e cativando o aluno em sua utilização. & & $\mathrm{X}$ & & \\
\hline 3. São usadas múltiplas mídias (imagens, animações, vídeos, música etc). & $\mathrm{X}$ & & & \\
\hline $\begin{array}{l}\text { 4. O tema é apresentado de forma lúdica e explora uma metáfora } \\
\text { esclarecedora para o aluno. }\end{array}$ & $\mathrm{x}$ & & & \\
\hline 5. Permite e incentiva a crescente autonomia e o envolvimento do aluno. & & $\mathrm{x}$ & & \\
\hline 6. O aluno consegue interagir com o programa facilmente. & & $\mathrm{x}$ & & \\
\hline 7. Existe interação com outros usuários. & & & & $\mathrm{x}$ \\
\hline $\begin{array}{l}\text { 8. Promove a criatividade (podem existem vários caminhos/ respostas/ } \\
\text { soluções). }\end{array}$ & & $\mathrm{X}$ & & \\
\hline $\begin{array}{l}\text { 9. O tempo de cada ação é adequado. Existe a possibilidade de repetição. } \\
\text { As etapas não são exaustivas. }\end{array}$ & $\mathrm{x}$ & & & \\
\hline $\begin{array}{l}\text { 10. As regras são coerentes e estão de acordo com o mundo imaginário } \\
\text { proposto. }\end{array}$ & & & & $\mathrm{x}$ \\
\hline $\begin{array}{l}\text { 11. O nível de concentração exigido está de acordo com o público do jogo. } \\
\text { Requisitos Pedagógicos }\end{array}$ & \multicolumn{3}{|c|}{ Requisitos Pedagógicos } & \\
\hline $\begin{array}{l}\text { 12. O conteúdo é coerente e contextualizado com a área e o nível de } \\
\text { ensino propostos. }\end{array}$ & $\mathrm{x}$ & & & \\
\hline $\begin{array}{l}\text { 13. O grau de dificuldade é variável, podendo ser definido pelo aluno ou } \\
\text { passando de níveis de dificuldade menor para maiores, de acordo com } \\
\text { os avanços obtidos. }\end{array}$ & & & & $\mathrm{X}$ \\
\hline 14. Aborda os conteúdos de forma a facilitar o aprendizado. & $\mathrm{x}$ & & & \\
\hline $\begin{array}{l}\text { 15. Oferece feedbacks construtivos, permitindo ao aluno identificar } \\
\text { claramente quando acertou e repensar suas ideias e estratégias } \\
\text { quando não forem bem sucedidas. }\end{array}$ & $\mathrm{x}$ & & & \\
\hline $\begin{array}{l}\text { 16. É dado algum incentivo ou premiação ao se atingir certos marcos, a } \\
\text { fim de motivar o aluno. }\end{array}$ & & & & $\mathrm{x}$ \\
\hline $\begin{array}{l}\text { 17. Faz referência ao universo cotidiano dos alunos, em uma perspectiva } \\
\text { de formação e de cidadania. }\end{array}$ & $\mathrm{x}$ & & & \\
\hline $\begin{array}{l}\text { Considerações I Sugestões de Melho } \\
\text { - Reduzir o texto do "Sobre" de forma a deixar mais claro e direto pensant } \\
\text { - Tela inicial apresenta um contexto mais próximo de desenho e as demai } \\
\text { que mostra uma certa incoerência. } \\
\text { - Textos menores e mais diretos para as perguntas e respostas. } \\
\text { Dar um destaque melhor para as respostas pois as mesmas aparecem } \\
\text { apenas melhore. }\end{array}$ & $\begin{array}{l}\text { també } \\
\text { telas sã }\end{array}$ & mais pró & $\begin{array}{l}\text { lico infan } \\
\text { has do re } \\
\text { ez negrit }\end{array}$ & \\
\hline
\end{tabular}

Pode-se verificar que o jogo teve uma boa avaliação, sendo que dos 17 itens, em oito a avaliadora considerou que ele atende plenamente e nenhum item foi marcado como "Não atende". Além disso, algumas opções foram marcadas como "Não se aplica”, por não fazerem parte do escopo e propósito do jogo. Porém, cinco itens foram 
marcados como “Atende parcialmente” e, além disso, a avaliadora contribuiu com algumas sugestões de melhoria, maioria voltadas para a forma de exibição das informações. Por exemplo, citou que havia certa divergência entre as figuras da tela inicial (apresentadas como desenho) e do restante do jogo (mais próximas do real). Os pontos levantados merecem atenção para futuras melhorias do jogo.

\section{Conclusões}

O objetivo desse artigo é apresentar o jogo Educa Trânsito, uma ferramenta a ser usada no processo de educação no trânsito. Um jogo que possui a característica de não focar apenas no ensino das leis e normas, mas trazer situações vividas na vida real por motoristas e, também, por pedestres que, por meio do exercício no jogo, agreguem conhecimentos que possam ser colocados em prática quando o usuário se encontrar naquela situação ou em ocasiões correlatas, na vida real.

O jogo possui um feedback apropriado para cada opção escolhida nos cenários com o objetivo de orientar o jogador. Isso permite que ela aja e reflita sobre as escolhas realizadas, o que pode levar a uma tomada de consciência sobre as consequências de suas ações no trânsito. Conforme Piaget (1977, p.196), "a tomada de consciência seria a passagem da ação à sua representação e comportaria sempre, portanto, uma reconstituição dependendo da conceituação [...]”.

No entanto, apesar de terem sido propostos sete cenários, apenas três foram desenvolvidos. Portanto, em trabalhos futuros, deverão ser acrescentados os demais cenários, além de levantar outros a serem acrescentados. Outro ponto importante consiste em separar os cenários por níveis de dificuldade.

É importante destacar que não é nossa intensão que o jogo seja usado como foco principal na abordagem do tema educação para o trânsito, devendo ser usado como ferramenta de apoio de iniciativas maiores, mais abrangentes e duradouras como feiras, palestras e projetos sociais que ocorrem, ou deveriam ocorrer, nas escolas com o objetivo de trabalhar temas transversais que, segundo o DENATRAN (2013, p. 29), “[...] não são novas disciplinas. São conteúdos educacionais - fundamentados em aspectos da vida social”, assim como ética e meio ambiente.

\section{Referências}

Albernaz, Jussara Martins. Jogo Computacional como Desencadeador da Aprendizagem de Matemática nas Séries Iniciais do ensino fundamental: sua avaliação por professores e alunos. Apostila. Vitória, 2008.

Assis, Gilda A.; Ficheman, Irene K.; Corrêa, Ana G. D.; Netto, Márcio L.; Lopes, Roseli de Deus. EducaTrans: um Jogo Educativo para o Aprendizado do Trânsito. Revista Novas Tecnologias na Educação (Renote), v. 4, n. 2. Porto Alegre, 2006.

CETIC. Centro de Estudos sobre as Tecnologias da Informação. TIC DOMICÍLIOS e USUÁRIOS 2012, 2012. Disponível em: <http://www.cetic.br/usuarios/tic/2012/>. Acesso em: 02 nov. 2013.

DENATRAN. Educação de trânsito no ensino regular. Disponível em: < http://www.denatran.gov.br/download/unidade\%202.pdf>. Acesso em 02 nov 2013.

Gardner, H. Frames of Mind: The Theory of Multiple Intelligences. New York: Basic Books, 1985. 
Hoffmann, Maria Helena; Filho, S. S. da Luz. A educação como promotora de comportamentos socialmente significativos no trânsito. In: Hoffmann, Maria Helena et al. Comportamento humano no trânsito. São Paulo: Casa do Psicólogo, 2003.

IBGE. Instituto Brasileiro de Geografia e Estatística. Acesso à Internet e posse de telefone móvel celular para uso pessoal. 2011. Disponível em: <http://www.ibge.gov.br/home/estatistica/populacao/acessoainternet/>. Acesso em: 25 out. 2013.

Macedo, G.M. A subjetividade e conflitos no trânsito urbano: desafios à política de educação e promoção de saúde. Cadernos da Escola Saúde Pública do Ceará. Vol2, n 1, 2006.

Moratori, Patrick Barbosa. Por que utilizer jogos educativos no processo de ensino aprendizagem? Rio de Janeiro, 2003. Disponível em: http://www.nce.ufrj.br/ginape/publicacoes/trabalhos/t_2003/t_2003_patrick_barbosa_m oratori.pdf. Acesso em: 06 nov. 2013.

Nascimento, E. L.; Nobre, Isaura A. M. XISOA - Um Processo de Desenvolvimento de Software baseado em Extreme Programming como alternativa para a construção de Objetos de Aprendizagem”. In: 15o CIAED (Congresso Internacional ABED de Educação a Distância), Fortaleza, 2009.

Nobre, Isaura A. M., Nunes, Vanessa Battestin, Gava, Tânia B. S., Fávero, Rutinelli. P., Bazet, Lydia M. B. Informática na Educação: um caminho de possibilidades e desafios. Editora Ifes: Vitória, 2011.

Pereira, Dalma Cintia; Passos, Maryze Lyra Silva. Jogos educativos: uma análise pedagógica para apoio à disciplina de português. In: Coletânia de artigos sobre informática na educação: construções em curso / organizadores, Rutinelli da Penha Fávero et al. - Serra: Ifes, 2012.

Piaget, Jean. A tomada de consciência. São Paulo: EDUSP/Melhoramentos, 1977. 